\title{
Wireless Sensor Network Based Solution for Water Quality Real-Time Monitoring
}

\author{
Shaimaa Khaled Nour El-Deen ${ }^{1}, *$, Hatem Elborai 1, \\ H.E.M. Sayour ${ }^{2}$, Ashraf Yahia ${ }^{1}$ \\ ${ }^{1}$ Physics Department, Faculty of Science, Ain Shams University, \\ Abbassia, Cairo, Egypt \\ ${ }^{2}$ Clinical Chemistry Unit, Department of Chemistry and Nutritional \\ Deficiency Diseases, Animal Health Research Institute, \\ Dokki, Cairo, Egypt
}

A low-cost wireless sensor network (WSN) solution for real-time monitoring of water quality is introduced and experimentally demonstrated. The investigated system provides monitoring of ammonia concentration in water which plays a critical role for aquatic organisms due to its toxic and hazardous effects on them. Additionally, the system can sense water $\mathrm{pH}$, water temperature, and ambient temperature. It is capable of periodically sensing different parameters, then sending parameters captured data to a virtual cloud called ThingSpeak that providing monitoring data remotely via internet through mobile phone or PC and analyzing them to send alert to the user when any parameter's value is out of its safety range. The proposed system can be used in several areas interested in water quality monitoring such as monitoring and contamination detection of water bodies (lakes, rivers, ponds, etc.). Also, it provides water quality monitoring in aquaculture, and aquaponics farms that help in enhancing food productivity and food security. Furthermore, it can be used for drinking water monitoring, irrigation water monitoring, etc.

\section{Introduction}

WATER quality has become a global issue that affects water resources, also aquaculture and aquaponics farms. Water quality is essential for ensuring the safety of water and healthy growth of aquatic organisms. Water quality is determined by several parameters such as temperature, $\mathrm{pH}$, ammonia, dissolved oxygen (DO), etc. These parameters may vary during the day depending on the external environmental conditions [1]. To keep healthy and sustainable environment for aquatic organisms, they need an adapted tolerance range of water parameters [2]. Accordingly, monitoring of these parameters allows effective water quality management to avoid the occurrence of unfavorable conditions that may be harmful for organisms [1]. For example, most aquatic organisms are 
affected by $\mathrm{pH}$ variation and may die if $\mathrm{pH}$ slightly changes from their adapted level $[2,3]$. Also, ammonia is toxic for aquatic organisms. In addition, it becomes more toxic as temperature and $\mathrm{pH}$ increases $[2,4]$. At high levels of ammonia, its toxic effects are instantaneous where numerous deaths of organisms occur quickly. In addition, the exposure to ammonia low levels over a long time causes aquatic animals stress, diseases, and more loss [2]. So, it is preferable to keep ammonia level at zero.

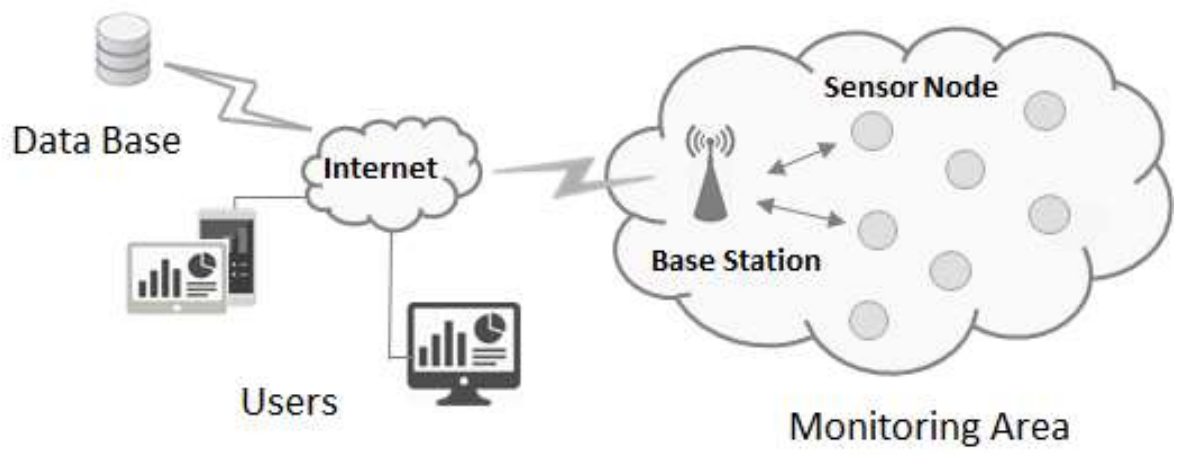

Fig. (1): Common wireless sensor network architecture that mainly consists of sensor nodes and base station node.

During the past decade, various water quality monitoring systems have been developed to provide researchers (or users) with information about the current health status of water bodies and their sustainability for aquatic organisms. The traditional water quality monitoring systems, that rely on water samples collection from field, testing and analyzing the collected samples in water laboratories, are not only expensive but also consume time and have a low resolution both in time and space [5]. On the other side, WSNs are recently regarded as potentially promising alternatives for water bodies monitoring with fine spatial and temporal resolution [5-10]. WSNs have a capability for real-time data capture, analysis and fast dissemination of information for making timely and appropriate decisions [5-7] [10,11, 12]. Fig. 1 shows a common WSN architecture that consists of sensor nodes and a base station node [6, 7] [9-13]. Sensor nodes measure the in-situ environmental parameters such as water temperature, and $\mathrm{pH}$, then transmit the collected data to a base station via wireless communication using ZigBee or some other communication protocol. Subsequently, base station (also called gateway) sends the collected data to a data base or a website through the internet in order to provide researchers (or users) with the desired data remotely from anywhere.

Recently, several research works have been carried out for water quality monitoring. Jiang et al. [14] proposed a water environment WSN monitoring system for temperature and $\mathrm{pH}$ hourly measurement. The system consists of monitoring nodes, base station, and remote monitoring center. Data were routed 
from monitoring nodes to the base station via ZigBee. Subsequently, they were transferred from base station to the remote monitoring center through groundpenetrating radars (GPRs). In Finland, Kotamäki et al. [15] developed a WSN for agriculture and water monitoring that remotly monitors water level, temperature, nitrate concentration, turibidity, as well as other air and soil parameters. In [16], Postolache et al. proposed a WSN solution for water quality parameters (electrical conductivity (EC), temperature, and turibidity) monitoring in urban areas which deployed ZigBee and Ethernet for local and remote data transfere, respectively. Besides, Lambrou et al. [17] developed a remote water quality monitoring and contamination detection in drinking water system that deploys ZigBee and Ethernet modules. This system is capable to monitor water flow, turbidity, $\mathrm{pH}$, oxidation reduction potential (ORP), EC, and temperature, then remotly send data via internet. Simbeye et al. [18] proposed a WSN system for aquaculture monitoring and controlling with a sleeping/wake-up mechanism for energy consumption minimization. This system consists of sensor nodes, gateway node, as well as PC. Sensor nodes measure water level, pH, DO, and temperature, send acquired data to gateway through ZigBee, and receive control signals from it for actuators control. Whereas, gateway node passes the received data to PC in order to provide graphical user interface (GUI) which was designed using LabWindows/CVI software platform.

Huang et al. [19] developed a self-configuration WSN for lake water quality monitoring that remotely monitors $\mathrm{pH}, \mathrm{EC}, \mathrm{DO}$, and temperature. Attivissimo et al. [20] designed and implemented a portable optical sensor to measure water turbidity and chlorophyll-a for in-situ seawater monitoring. In [21], a water quality monitoring system based on ISO/IEC/IEEE 21451 sea water probe with the ability to measure water turbidity, chlorophyll-a, temperature, and conductivity/ salinity was proposed by Adamo et al. This system used a GPRS module to provide real-time data over spatial coordinates. Chandanapalli et al. [1] designed a WSN system for intensive aquaculture monitoring. It consists of four sensors nodes and a receiver station. The sensors nodes monitor $\mathrm{pH}$, temperature inside and outside water, and humidity, then transmit collected data through GSM to the receiver station which stores data in a PC which provides GUI. Vijayakumar and Ramya [22] designed an IoT (internet of things) system to monitor temperature, $\mathrm{pH}, \mathrm{DO}$, turbidity, and conductivity of water, also send sensors data to a web server from which they can be viewed anywhere.

In this paper, a novel design of WSN based solution for remotely water quality monitoring in real-time has been introduced and experimentally demonstrated. This system consists of sensor nodes and gateway. Sensor nodes monitor several parameters $(\mathrm{pH}$, temperature inside and outside water, and ammonia), then transfer collected data to the gateway which uploading them to the cloud through Ethernet shield. The investigated design has several advantageous such as cost-effective, light-weight, and self-organization. 
Additionally, it supports sleep/wake-up mechanisms for power saving and has a programmable rate for parameters sensing and acquired data reporting which can be adjusted for each parameter. Moreover, to the best of the authors knowledge, this system provides monitoring of ammonia, which was not monitored before in previous studies in spite of its toxic and hazardous effects on aquatic organisms. Table (1) shows the characteristics of previous systems and our proposal.

Table (1): Summary of characteristics of previous systems and our proposal.

\begin{tabular}{|c|c|c|c|c|c|c|c|c|c|c|}
\hline Paper & [1] & [13] & [14] & [15] & [16] & [17] & [18] & [20] & {$[21]$} & Our Proposal \\
\hline $\begin{array}{l}\text { Communication } \\
\text { technology }\end{array}$ & GSM & $\begin{array}{l}\text { ZigBee } \\
\text { / GPRs }\end{array}$ & $\begin{array}{l}\text { GSM/ } \\
\text { GPRs }\end{array}$ & $\begin{array}{l}\text { Zigbee/ } \\
\text { Ethernet }\end{array}$ & $\begin{array}{l}\text { Zigbee/ } \\
\text { Ethernet }\end{array}$ & Zigbee & $\begin{array}{l}\text { ZigBee/ } \\
\text { GPRs }\end{array}$ & $\begin{array}{l}\text { RF/ GSM/ } \\
\text { GPRs }\end{array}$ & WiFi & $\begin{array}{l}\text { Low power RF/ } \\
\text { Ethernet }\end{array}$ \\
\hline Applied on & pond & $\begin{array}{l}\text { Artifici } \\
\text { al lake }\end{array}$ & River basin & $\begin{array}{c}\text { Laboratory } \\
\text { test }\end{array}$ & $\begin{array}{l}\text { Water } \\
\text { pipe }\end{array}$ & Ponds & $\begin{array}{c}\text { Laboratory } \\
\text { test }\end{array}$ & Sea coast & & Tank \\
\hline alarm? & $\mathrm{x}$ & $\mathrm{x}$ & $\mathrm{x}$ & & $\mathrm{x}$ & & & $\mathrm{x}$ & & $\mathrm{x}$ \\
\hline $\mathrm{pH}$ & $\mathrm{x}$ & $\mathrm{x}$ & & & $\mathrm{x}$ & $\mathrm{x}$ & $\mathrm{x}$ & & $\mathrm{x}$ & $\mathrm{x}$ \\
\hline Water temperature & $\mathrm{x}$ & $\mathrm{x}$ & $\mathrm{x}$ & $\mathrm{x}$ & $\mathrm{x}$ & $\mathrm{x}$ & $\mathrm{x}$ & $\mathrm{x}$ & $\mathrm{x}$ & $\mathrm{x}$ \\
\hline Air temperature & $\mathrm{x}$ & & $\mathrm{x}$ & & & & & & & $\mathrm{x}$ \\
\hline Ammonia & & & & & & & & & & $\mathrm{x}$ \\
\hline DO & & & & & & $\mathrm{x}$ & $\mathrm{x}$ & & $\mathrm{x}$ & \\
\hline ORP & & & & & $\mathrm{x}$ & & & & & \\
\hline Water level & & & $\mathrm{x}$ & & & $\mathrm{x}$ & & & & \\
\hline Water flow & & & & & $\mathrm{x}$ & & & & & \\
\hline Nitrate & & & $\mathrm{x}$ & & & & & & & \\
\hline Turbidity & & & $\mathrm{x}$ & $\mathrm{x}$ & $\mathrm{x}$ & & & $\mathrm{x}$ & $\mathrm{x}$ & \\
\hline EC & & & & $\mathrm{x}$ & $\mathrm{x}$ & & $\mathrm{x}$ & $\mathrm{x}$ & $\mathrm{x}$ & \\
\hline Humidity & $\mathrm{x}$ & & & & & & & & & \\
\hline Chlorophyll-a & & & & & & & & $\mathrm{x}$ & & \\
\hline Other parameters & & & $\begin{array}{l}\text { Air and soil } \\
\text { parameters }\end{array}$ & & & & & & & \\
\hline $\begin{array}{c}\text { Total of monitoring } \\
\text { parameters }\end{array}$ & 4 & 2 & 10 & 3 & 6 & 4 & 4 & 4 & 5 & 4 \\
\hline
\end{tabular}

\subsection{Hardware}

\section{System Architecture}

The proposed system consistis of two different nodes types; sensor node as well as gateway (Fig. 2). Sensor node includes power supply unit, sensing module, Arduino (microcontroller), and wireless transceiver module. Sensing module includes $\mathrm{pH}$ and ammonia probes associated with appropriate interface circuits (include amplifiers and other components), also includes water temperature and ambient temperature sensors. Arduino is used to manage node functions and tasks, process data, send data to a base station and receive instructions from it through the wireless transceiver module. Whereas, base station consists of power supply unit, Arduino, wireless transceiver module, and Ethernet shield. Base station manages, organizes, and controls the WSN actions, also passes data between users and the network via the Ethernet shield to provide remote accessibility of information which enables users to collect and analyze data remotly from any location. 


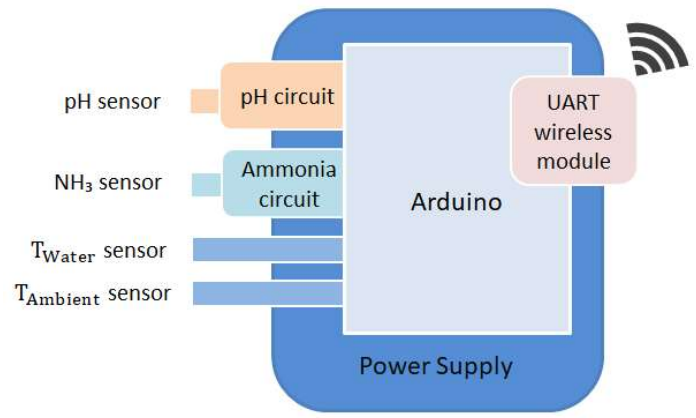

a- Sensor Node

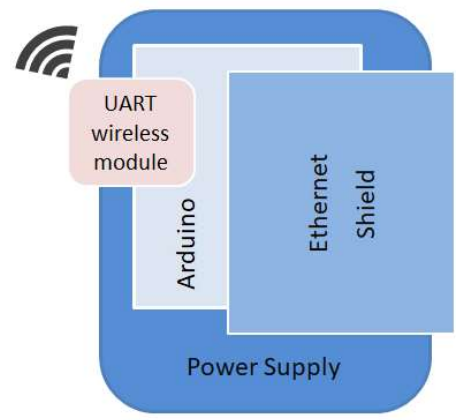

b- Base Station (Gateway)

Fig. (2): Proposed monitoring system different nodes: (a) Sensor node, and (b) Gateway.

\subsection{1. pH Module}

$\mathrm{pH}$ of a solution can be determined by $\mathrm{pH}$ glass electrode which is a combination electrode (Fig. 3) that mainly consists of glass electrode (called measuring electrode), and reference electrode. Basically, $\mathrm{pH}$ is determined according to the electrode transfer function by measuring the potential difference between glass and reference electrodes [23]. The transfer function is based on Nernst equation $[23,24]$ that relates $\mathrm{pH}$ of the measuring solution to the electrode output and the solution temperature, and is represented as:

$$
p H(X)=p H(S) \frac{F}{R T \ln 10}(E s-E X)^{1}
$$

According to this function, $\mathrm{pH}$ electrode sensitivity $(R T \ln 10 / \mathrm{F} 1 \mathrm{pH}(X)$ is $\mathrm{pH}$ of unknown solution $(X), p H(S)$ is $\mathrm{pH}$ of standard solution $=7, E S$ is the electric potential at reference or standard electrode, $E X$ is the electric potential at $\mathrm{pH}$-measuring electrode, $R$ is the molar gas constant (8.314510 J mol-1 K-1), $T$ is the temperature in Kelvin, and $F$ is Faraday constant $(9.6485309 * 104 \mathrm{C}$ mol-1). or $0.19842 T(\mathrm{mV} / \mathrm{pH})$ ) linearly increases with temperature [23]. Consequently, the electrode sensitivity is $59.16 \mathrm{mV} / \mathrm{pH}$ at $25^{\circ} \mathrm{C}$ which produces an output voltage $(E S-E X)$ from $+414.12 \mathrm{mV}(0 \mathrm{pH})$ to $-414.12 \mathrm{mV}(14 \mathrm{pH})$. Whereas, at $100^{\circ} \mathrm{C}$, the output will be from $+518.28 \mathrm{mV}(0 \mathrm{pH})$ to $-518.28 \mathrm{mV}$ $(14 \mathrm{pH})$ with a $74.04 \mathrm{mV} / \mathrm{pH}$ sensitivity. Therefore, measuring of solution temperature is important to determine its correct $\mathrm{pH}$ value [23].

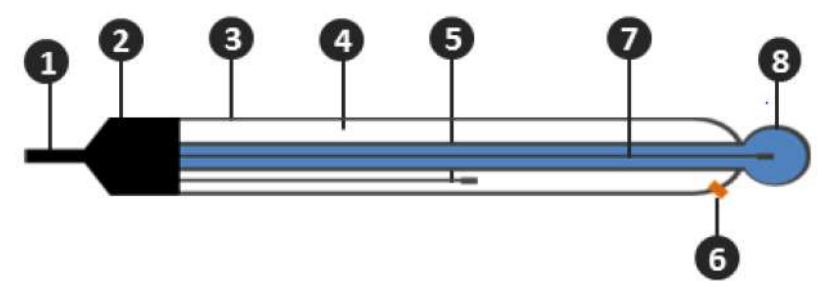

Fig. (3): pH glass electrode combination: 1- cable, 2- cap, 3- body-glass or epoxy, reference electrode (4- reference chamber filled with internal-fill solution, 5reference wire, 6- diaphragm), and glass electrode (7- $\mathrm{pH}$ wire immersed in a buffer solution $+\mathrm{KCl}(\mathrm{pH}=7)$, 8- $\mathrm{pH}$ sensitive glass membrane). 
It is worth mentioning that $\mathrm{pH}$ electrode has high impedance which is typically in the range of $10 \mathrm{M} \Omega$ to $1000 \mathrm{M} \Omega$ [23]. So, its output cannot be used directly by other components (like ADC, Microcontroller, etc.) due to impedance mismatching. Therefore, a high-input impedance buffer is needed for impedance matching [23]. Besides, the electrode produces a bipolar signal which does not suitable for single-supply components. Therefore, an op-amp is required for signal level shifting. These characteristics should be considered to design the $\mathrm{pH}$ interface circuit [23]. Fig. (4) shows $\mathrm{pH}$ interface circuit design using kicad software. The gain of the first stage TL072 operational amplifier is 3 $\left(G_{1}=1+R_{2} / R_{1}\right)$. As mentioned before, based on the Nernst equation, at $25^{\circ} \mathrm{C}$ the electrode output is swing from $0.414 \mathrm{~V}$ to $-0.414 \mathrm{~V}$. So, the first stage output will swing from $3 \mathrm{x}$ $0.414 \mathrm{~V}=1.242 \mathrm{~V}$ down to $3 \mathrm{x}-0.414=-1.242 \mathrm{~V}$. In the second stage, called offset stage, a unity gain $\left(G_{2}=-R 4 / R 3\right)$ TL072 op-amp was used for signal level shifting using $1 \mathrm{~K} \Omega$ and $5 \mathrm{~K} \Omega$ resistors (Fig. 4). The offset voltage is $1.67 \mathrm{~V}$ according to the following equation:

$$
V_{\text {offset }}=\left(1+\frac{R_{4}}{R_{3}}\right)\left(\frac{R_{6}}{R_{6}+R_{7}}\right) V_{c c}
$$

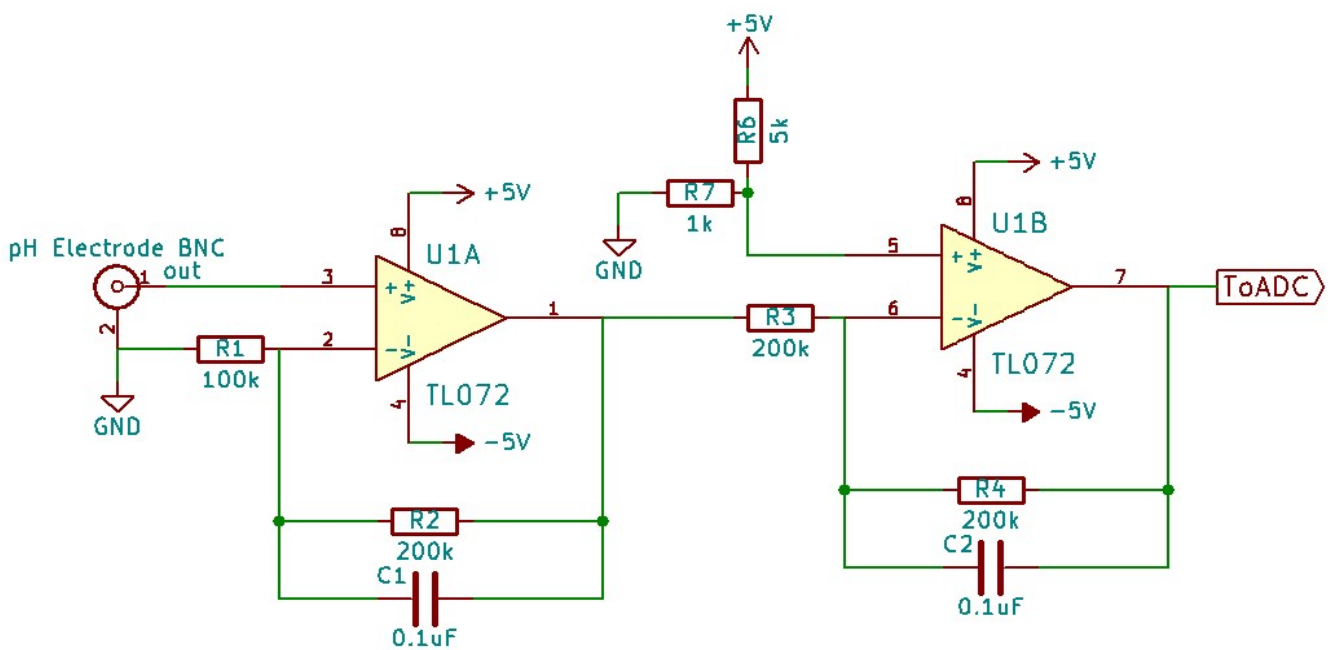

Fig. (4): $\mathrm{pH}$ interface circuit design using Kicad software.

that produces an output $\left(V_{\text {out }}\right.$ ) from $-1.242+1.67=0.428 \mathrm{~V}$ to $1.242+1.67=2.912 \mathrm{~V}$. Accordingly, Arduino determines the electrode output from $\mathrm{pH}$ module output using the following equation:

$$
(E s-E x)=\left(V_{o u t}-V_{o f f s e t}\right) / G 1 G 2
$$

Subsequently, It calculates $\mathrm{pH}$ value using Nernst equation.

\subsubsection{Ammonia (NH3) Module}

Ammonia is determined by ammonia gas ion selective electrode (ISE), Fig. (5). It consists of gas-permeable membrane, $\mathrm{pH}$ glass electrode, and reference electrode [25]. The membrane separates the measuring solution from the electrode internal solution [25]. Dissolved ammonia in the measuring solution 
diffuses through the membrane until the partial pressure of ammonia is the same on both sides of it, dissolves in the internal solution, reacts with water in the internal solution producing $\mathrm{OH}$ - ions which increasing $\mathrm{pH}$ of the internal solution [25], and consequently changes the electrode output that responses to ammonia concentration in a Nernstian manner. Thus, from the previous description of the ammonia electrode, the interface circuit design of ammonia electrode is similar to that of the $\mathrm{pH}$ electrode (Fig. 4) with different components values suitable for ammonia electrode output range.

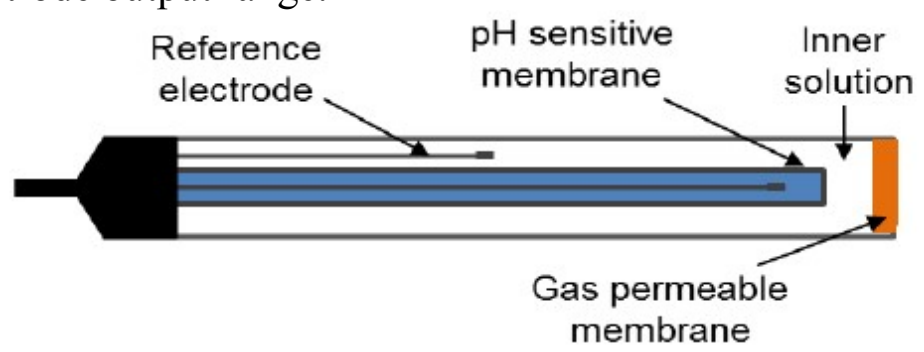

Fig. (5): Ammonia ion selective electrode combination.

\subsubsection{Temperature Sensors}

DS18B20 is used for water temperature sensing. It is a 1-Wire digital temperature sensor for temperature measurement from $-55^{\circ} \mathrm{C}$ to $+125^{\circ} \mathrm{C}$ with $\pm 0.5^{\circ} \mathrm{C}$ accuracy from $-10^{\circ} \mathrm{C}$ to $+85^{\circ} \mathrm{C}$. DS18B20 provides a programmable resolution from 9-bit to 12-bit. It requires $750 \mathrm{~ms}$ as a maximum temperature conversion time in case of 12-bit resolution. Besides, it requires only one data line with ground to communicate with a microcontroller, where each DS18B20 sensor has its unique 64-bit serial code that allowing multiple sensors to be addressed on the same data bus [26].

Whereas, LM35 is used for ambient temperature measurement. LM35 is a precision integrated-circuit temperature device that measures temperature from $-55^{\circ} \mathrm{C}$ to $150^{\circ} \mathrm{C}$ with accuracy $\pm 0.5^{\circ} \mathrm{C}$ at $25^{\circ} \mathrm{C}$, and $\pm 1^{\circ} \mathrm{C}$ from $-55^{\circ} \mathrm{C}$ to $150^{\circ} \mathrm{C}$. Its output voltage is linearly proportional to centigrade temperature with a slope of $10.0 \mathrm{mV} /{ }^{\circ} \mathrm{C}$, where centigrade temperature is easily calculated from the following transfer function [27]:

$$
T=\operatorname{Vout}(\mathrm{mV}) / 10.0\left(\mathrm{mV} /{ }^{\circ} \mathrm{C}\right)
$$

\subsubsection{Arduino}

Sensor node includes Arduino Nano. Arduino Nano is a small microcontroller board based on the ATmega328. This board runs at $16 \mathrm{MHz}$, and has $32 \mathrm{~KB}$ of flash memory, $1 \mathrm{~KB}$ EEPROM, $2 \mathrm{~KB}$ internal SRAM, 22 digital input/ output pins of which 6 can be used as PWM (Pulse-width modulation) outputs, USB connector, and 8 analog inputs with 10-bit resolution for each input pin [28]. 
On the other side, Arduino Mega 2560, based on ATmega2560, was selected for the gateway node. Mega is designed for more complex operations. It runs at $16 \mathrm{MHz}$, has 54 input/output digital pins (of which 15 are used as PWM outputs), 16 analog inputs with 10-bit resolution for each input pin, larger space (256 KB flash memory, 4 KB EEPROM, $8 \mathrm{~KB}$ internal SRAM), 4 UARTs (hardware serial ports), and a USB connection [29].

\subsubsection{Wireless Transceiver Module}

It is a serial UART wireless module based on Texas instrument CC1101, $200 \mathrm{~m}$ distance range in the straight line open environment, and $433 \mathrm{MHz}$ frequency that establishes wireless communication between nodes. It is very similar to Zigbee but much cheaper. It can work as one to many. Its parameters (baud rate, channel, and power $\mathrm{dBm}$ ) can be adjusted by AT command [30].

\subsubsection{Arduino Ethernet Shield}

\subsection{Software}

The Ethernet shield, based on W5100 chip, allows Arduino boards to connect to internet for establishing communication between users and the WSN, serving up sensor data, making an e-mail notification, controlling things through internet easily, etc. This shield has a micro-SD card slot for data storage, and a Power over Ethernet (POE) module for power extraction from the Ethernet cable [31].

Figure (6) elucidates software flowchart of gateway and sensor nodes. Sensor nodes start initializing clock, ADC, serial port, etc. Then, each sensor node enters sleep mode, for power consumption saving, waiting for an interrupt signal from gateway to go into wake up mode, capture parameters data, then send them to gateway. After the data are received by gateway, sensor node returns sleep mode and waits for the next interrupt signal. On the other side, gateway starts initializing clock, ADC, serial port, etc. After a predefined time for parameters scanning, it sends an interrupt signal to sensor node 1, then waiting for receiving parameters data from it. After receiving data successfully, gateway uploads data to the cloud (ThingSpeak cloud) providing remote access of data from any location. Then, gateway repeats data requesting, gathering, and uploading for each sensor node. Finally, gateway waits for the next scanning time to repeat the whole process again.

\section{Results And Discussions}

In this section, the results are shown. First, the calibration process of sensors ( $\mathrm{pH}$, ammonia, water temperature, ambient temperature sensors) has been carried out in order to check their effectiveness working operation. $\mathrm{pH}$ and ammonia probes have been calibrated by Orion $\mathrm{pH} / \mathrm{mv}$ benchtop meter. 
Additionally, $\mathrm{pH}$ and ammonia interface circuits have been designed and tested with proteus simulator. After simulation, the circuits have been implemented. Then, $\mathrm{pH}$ and ammonia sensors have been calibrated again with the interface circuits to check their operation which were similar to calibration data that carried out using Orion meter. Through calibration the sensitivity of $\mathrm{pH}$ electrode has been determined, also ammonia response curve (Fig. 7) has been obtained which was similar to direct calibration curve mentioned in Thermo Scientific user guide [32]. The obtained calibration data are used by the system to determine $\mathrm{pH}$ and ammonia values of water. Also, parameters sampling time have been selected which can be easily adjusted as required for each parameter. Finally, the system has been implemented on a fish tank. The system collects and sends all parameters data to a database (ThingSpeak) from which users can access a detailed information about system parameters in real-time from any location.
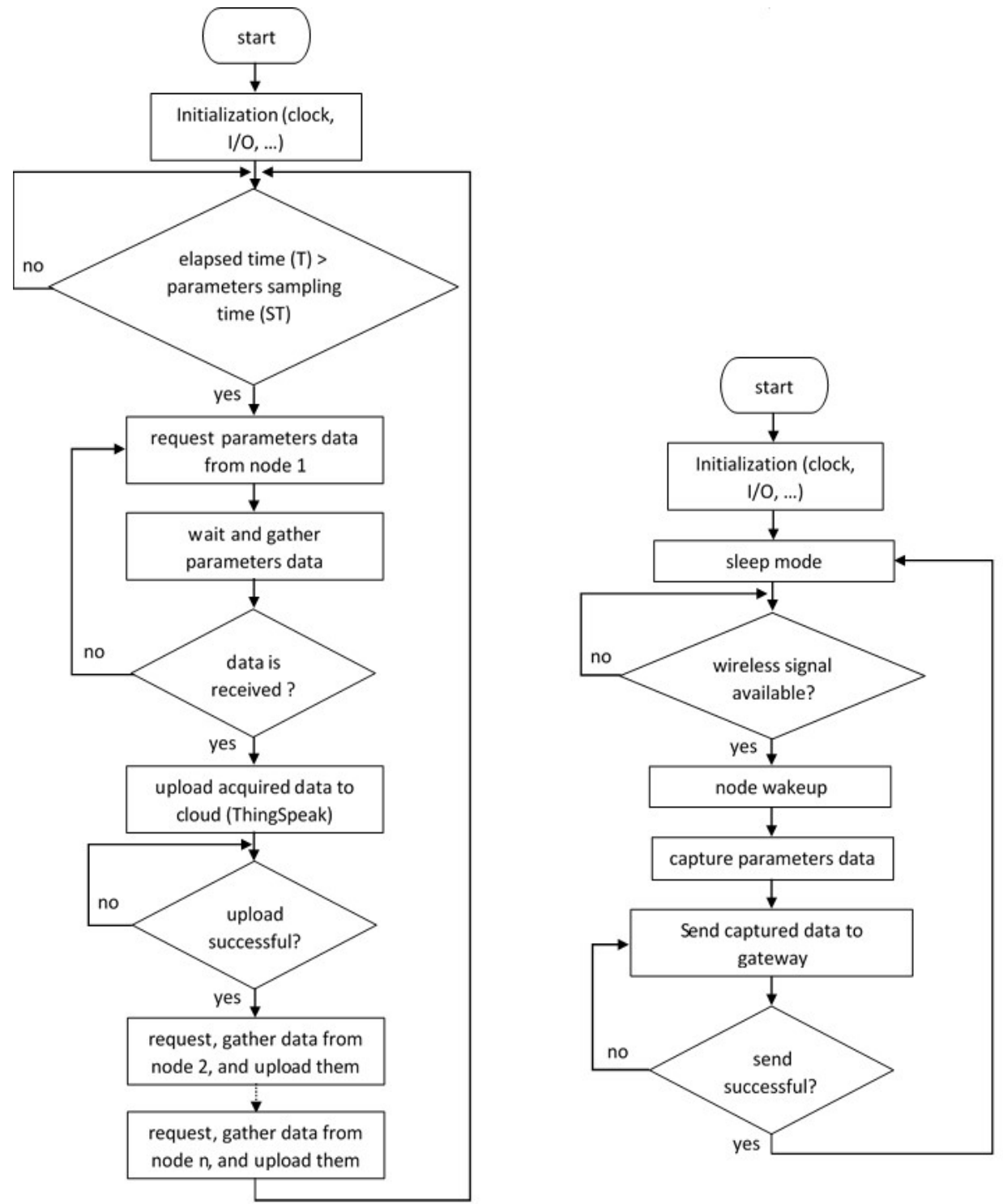

Fig. (6): Software flow diagram for: (a) gateway node, (b) sensor node. 
ThingSpeak is an open source IoT platform with MATLAB analytics. It enables storing and retrieving sensors data using HTTP protocol, analyzing and visualizing them in historical charts, plots, or gauges, as well as acting on data by, for example, sending a tweet (which can then be easily forwarded to a mobile phone via SMS) when some parameter value becomes out of its normal range, remotely controlling devices like oxygen aerator to keep optimum oxygen level in water, etc . [33]. Fig. (8) shows the captured data on Thing Speak IoT cloud which includes four fields for $\mathrm{pH}$, water temperature, ambient temperature, and ammonia data. It is exhibited that the ambient temperature rises daily from sunrise until sunset. After sunset, it begins to decrease until sunrise the next day. However, on August 5 from 9:04 AM to 11:05 AM, the ambient temperature dropped from $33.4^{\circ} \mathrm{C}$ to $27.1^{\circ} \mathrm{C}$ because the air conditioner was turned on. Water temperature rises/ decreases as ambient temperature rises/ decreases. But changes in water temperature lag behind ambient temperature because of the high heat capacity of water. $\mathrm{pH}$ of water is affected by several factors such as water temperature, carbon dioxide, etc. [2]. Concerning the temperature effect, $\mathrm{pH}$ and water temperature have an inverse relationship [2] which is elucidated by water temperature and $\mathrm{pH}$ data (Fig. 8(a) and (b)). However, ammonia zero readings, Fig. (8d), indicate that water has zero ammonia concentration which is the desired condition of sustainable environment for aquatic organisms.

Table (2): Cost of sensor node and gateway.

\begin{tabular}{lcc}
\hline Item & Units & Cost $(\$)$ \\
\hline Sensor node: & & \\
\hline Arduino nano & 1 & 4.47 \\
Wireless UART module & 1 & 6.7 \\
\hline Gateway: & & \\
\hline Arduino mega & 1 & 13.69 \\
Ethernet shield & 1 & 9.78 \\
Wireless UART module & 1 & 6.7 \\
\hline Total cost & & 41.34 \\
\hline
\end{tabular}

The cost of sensor node and gateway (Fig. 9) is $\$ 41.34$ as shown in Table 2 , which is a low cost compared to other commercially available systems cost. Besides, the system supports addition of another analog or ISE sensors (like nitrite, nitrate, etc.) up to seven sensors, also supports digital sensors addition up to another six sensors. So, a more advanced arduino board should be used to exceed the number of sensors integrated into the system if needed. 


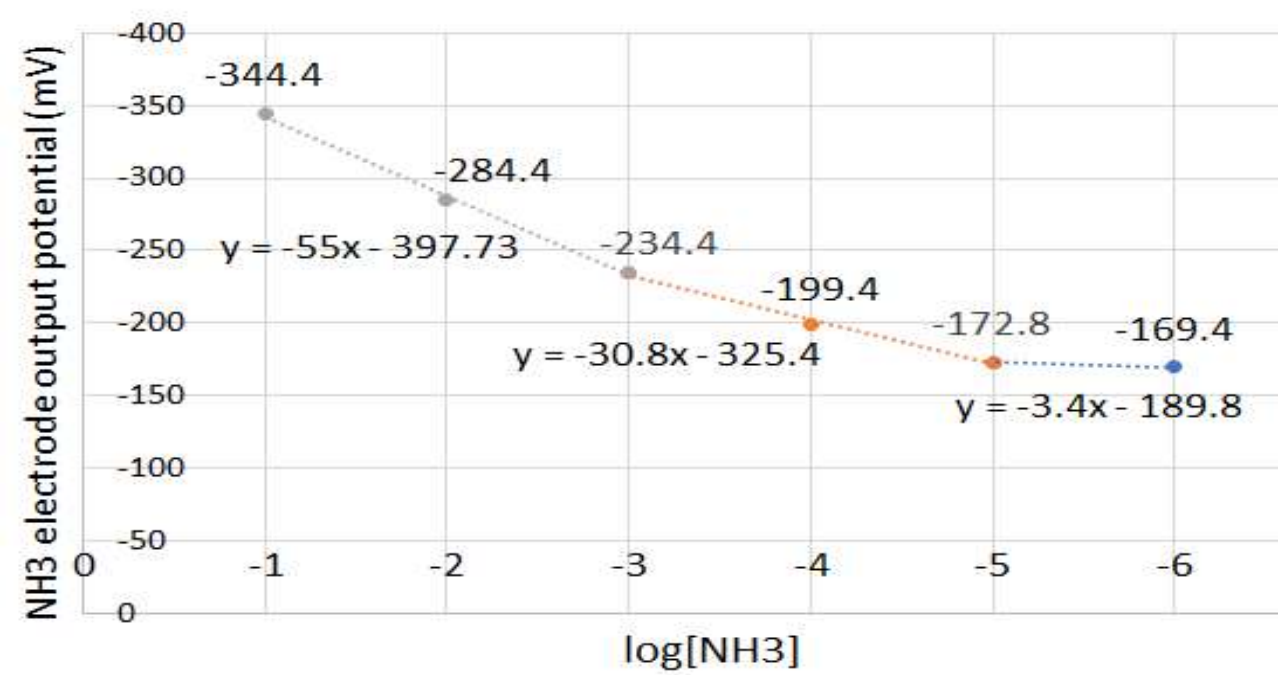

Fig. (7): NH3 electrode response curve by using ammonia interface circuit which represents the electrode outputs that are calculated from the interface outputs at different concentrations of ammonia.

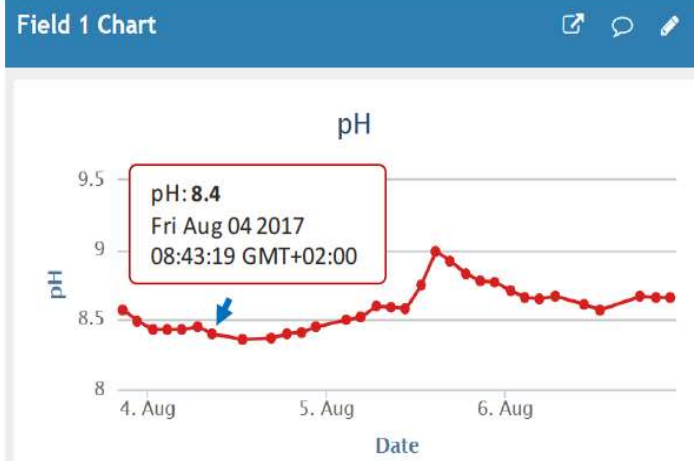

(a)

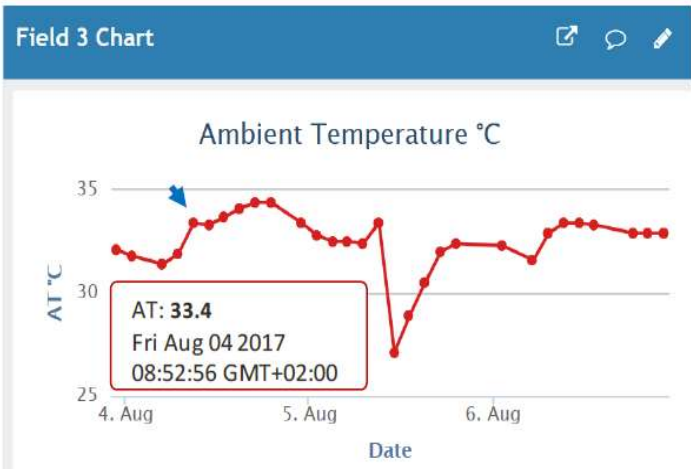

(c)

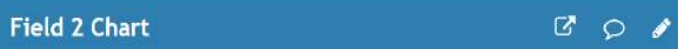

Water Temperature ${ }^{\circ} \mathrm{C}$

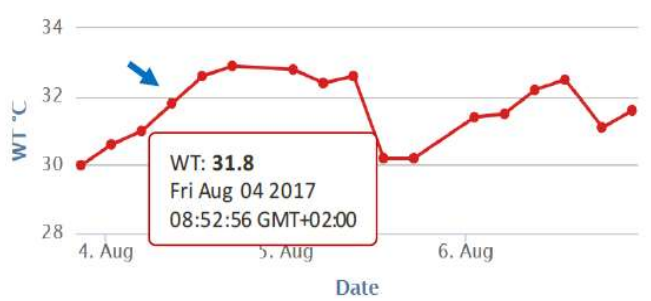

(b)
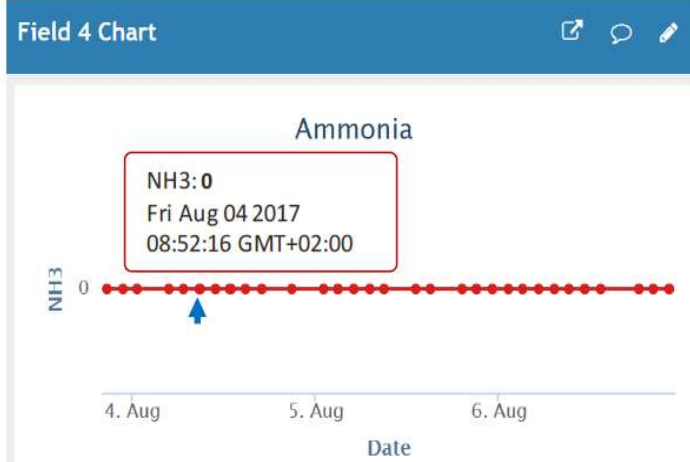

(d)

Fig. (8): Real-time monitoring data captured from a fish tank: (a) $\mathrm{pH}$ data, (b) water temperature data, (c) air (ambient) temperature data, (d) ammonia data (ammonia zero readings indicate that water has zero ammonia concentration which is the desired condition of a sustainable environment for aquatic organisms). 


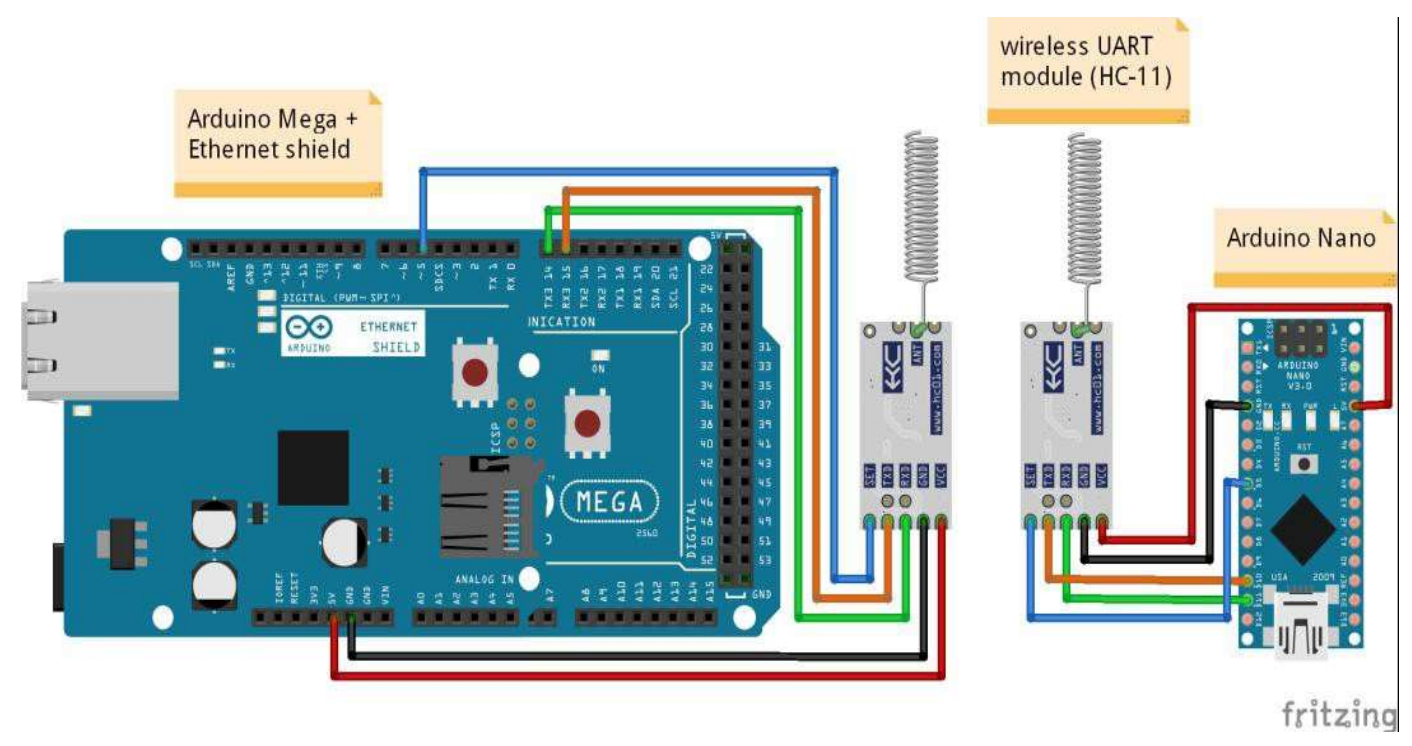

Fig. (9): Gateway (Arduino Mega + Ethernet shield + HC-11 module), and Sensor node (Arduino Nano+ HC-11 module) Hardware.

\section{Conclusion}

The present solution is effectively capable of several water parameters and ambient temperature continuously monitoring in real-time which can be easily expanded to monitor other parameters. It monitors ammonia concentration in water, where none of previous studies monitored it in spite of its toxic and hazardous effects on aquatic organisms. Also, water $\mathrm{pH}$, and water temperature are monitored. It is a low cost, compact, lightweight system with self-organization and automatic operation capabilities that does not require human presence in field. Moreover, it supports sleep/wake-up mechanisms for power saving and has a programmable sampling frequency for parameters scanning. Besides, the system avoids some traditional monitoring systems drawbacks such as low temporal and spatial resolution, slow response, and failure to make the necessary decisions in proper time. Captured data demonstrate the real-time monitoring capability of WSN technology which provides the desired information for water quality management that in turn helping enhance fish and plants yield, reduce the occurrence of largescale fish and plants diseases, enhance projects economics, improve food safety, and enhance human health. Although, monitoring only is effective to identify the problem and help take a strategic decision to solve it in time, actuators can be easily integrated into the system for parameters automatic controlling.

In future, the plan is to expand the present system to monitor more parameters (DO, turbidity, nitrite, nitrate, EC, etc.), add actuators (aerator, feeder, heater, etc.) for smart controlling, use GSM/GPRs shield for more flexible communication capability, and replace large electrodes with printed sensors array to minimize sensor node size. 


\section{References}

1. S.B. Chandanapalli, E.S. Reddy, D.R. Lakshmi, Design and deployment of aqua monitoring system using wireless sensor networks and IAR-Kick, J. Aquac. Res. Dev. 5 (2014).

2. C. Somerville, M. Cohen, E. Pantanella, A. Stankus, A. Lovatelli, Smallscale aquaponic food production: integrated fish and plant farming, Food and Agriculture Organization of the United Nations, 2014. (accessed July 14, 2017).

3. F. Ahmed, Development and implementation of Wireless Sensor Networks for measuring water quality, Lamar University-Beaumont, 2014.

4. W.A. Wurts, Daily pH cycle and ammonia toxicity, World Aquac. 34 (2003) 20-21.

5. M.H. Gholizadeh, A.M. Melesse, L. Reddi, A Comprehensive Review on Water Quality Parameters Estimation Using Remote Sensing Techniques, Sensors. 16 (2016) 1298. (accessed July 14, 2017).

6. J. Yick, B. Mukherjee, D. Ghosal, Wireless sensor network survey, Comput. Networks. 52 (2008) 2292-2330.

7. P. Rawat, K.D. Singh, H. Chaouchi, J.M. Bonnin, Wireless sensor networks: a survey on recent developments and potential synergies, J. Supercomput. 68 (2014) 1-48.

8. I.F. Akyildiz, W. Su, Y. Sankarasubramaniam, E. Cayirci, Wireless sensor networks: a survey, Comput. Networks. 38 (2002) 393-422.

9. G. Xu, W. Shen, X. Wang, Applications of Wireless Sensor Networks in Marine Environment Monitoring: A Survey, Sensors. 14 (2014) 16932. (accessed July 14, 2017).

10. M. Zennaro, Wireless Sensor Networks for Development: Potentials and Open Issues, KTH, 2010. (accessed July 14, 2017).

11. D. Izadi, Enhancing wireless sensor networks functionalities, Deakin University, 2014. (accessed July 14, 2017).

12. L. Parra, S. Sendra, L. García, J. Lloret, Design and Deployment of LowCost Sensors for Monitoring the Water Quality and Fish Behavior in Aquaculture Tanks during the Feeding Process, Sensors . 18 (2018). (accessed October 17, 2018).

13. [13] M.A. Matin, M.M. Islam, Overview of Wireless Sensor Network, in: M.A. Matin (Ed.), Wirel. Sens. Networks - Technol. Protoc., InTech, Rijeka, 2012: p. Ch. 01 (accessed July 14, 2017).

14. P. Jiang, H. Xia, Z. He, Z. Wang, Design of a water environment monitoring system based on wireless sensor networks, Sensors. 9 (2009) 6411-6434. (accessed July 14, 2017).

15. N. Kotamäki, S. Thessler, J. Koskiaho, A.O. Hannukkala, H. Huitu, T. Huttula, J. Havento, M. Järvenpää, Wireless in-situ sensor network for agriculture and water monitoring on a river basin scale in southern Finland: 
Evaluation from a data user's perspective, Sensors. 9 (2009) 2862-2883. (accessed July 14, 2017).

16. O. Postolache, J.D. Pereira, P. Silva Girão, Wireless sensor network-based solution for environmental monitoring: water quality assessment case study, IET Sci. Meas. Technol. 8 (2014) 610-616. (accessed July 14, 2017).

17. T.P. Lambrou, C.C. Anastasiou, C.G. Panayiotou, M.M. Polycarpou, A lowcost sensor network for real-time monitoring and contamination detection in drinking water distribution systems, IEEE Sens. J. 14 (2014) 2765-2772.

18. D.S. Simbeye, J. Zhao, S. Yang, Design and deployment of wireless sensor networks for aquaculture monitoring and control based on virtual instruments, Comput. Electron. Agric. 102 (2014) 31-42.

19. X. Huang, J. Yi, S. Chen, X. Zhu, A Wireless Sensor Network-Based Approach with Decision Support for Monitoring Lake Water Quality, Sensors. 15 (2015) 29273-29296. (accessed July 14, 2017).

20. [20] F. Attivissimo, C.G.C. Carducci, A.M.L. Lanzolla, A. Massaro, M.R. Vadrucci, A portable optical sensor for sea quality monitoring, IEEE Sens. J. 15 (2015) 146-153.

21. F. Adamo, F. Attivissimo, C.G.C. Carducci, A.M.L. Lanzolla, A smart sensor network for sea water quality monitoring, IEEE Sens. J. 15 (2015) 2514-2522.

22. N. Vijayakumar, R. Ramya, The real time monitoring of water quality in IoT environment, in: 2015 Int. Conf. Circuits, Power Comput. Technol. [ICCPCT-2015], 2015: pp. 1-4. (accessed July 14, 2017).

23. Designing with $\mathrm{pH}$ Electrodes. (accessed July 14, 2017).

24. A.J. Bard, L.R. Faulkner, J. Leddy, C.G. Zoski, Electrochemical methods: fundamentals and applications, wiley New York, 1980.

25. Ammonia Gas Sensing Combination Electrode. (accessed July 14, 2017).

26. DS18B20 Temperature Sensors Datasheet. (accessed April 15, 2017).

27. LM35 Precision Centigrade Temperature Sensors Datasheet. (accessed April 15, 2017).

28. Arduino Nano. (accessed April 15, 2017).

29. Arduino Mega. (accessed April 15, 2017).

30. Wireless Module Serial UART (200M Range-433 MHz). (accessed April 15, 2017).

31. Arduino Ethernet Shield. (accessed April 15, 2017).

32. Ammonia ISE Thermo Scientific user guide. (accessed April 15, 2017).

33. How To Collect, Analyze, and Act on IoT Data - ThingSpeak IoT. (accessed April 15, 2017). 